\title{
Nanostructure and Luminescent Properties of Bimetallic Lanthanide Eu/Gd, Tb/Gd and Eu/Tb Coordination Polymers
}

\author{
Helena Brunckova ${ }^{1, *}$, , Erika Mudra ${ }^{1}$, Lucas Rocha ${ }^{2}{ }^{\oplus}$, Eduardo Nassar $^{2}$, Willian Nascimento ${ }^{2}$, \\ Hristo Kolev ${ }^{3}{ }^{1}$, Maksym Lisnichuk ${ }^{1}$, Alexandra Kovalcikova ${ }^{1}$, Zuzana Molcanova ${ }^{1}$, Magdalena Strečkova ${ }^{1}$ \\ and Lubomir Medvecky ${ }^{1}$ (D) \\ 1 Institute of Materials Research, Slovak Academy of Sciences, Watsonova 47, 04001 Kosice, Slovakia; \\ emudra@saske.sk (E.M.); mlisnichuk@saske.sk (M.L.); akovalcikova@saske.sk (A.K.); \\ molcanova@saske.sk (Z.M.); mstreckova@saske.sk (M.S.); lmedvecky@saske.sk (L.M.) \\ 2 Universidade de Franca, Science \&Technology, Av. Armando Salles Oliveira 201, Franca 14404-600, Brazil; \\ lucas.rocha@unifran.edu.br (L.R.); eduardo.nassar@unifran.edu.br (E.N.); willianenmelo@outlook.com (W.N.) \\ 3 Institute of Catalysis, Bulgarian Academy of Sciences, Acad. G. Bonchev St., BU-1113 Sofia, Bulgaria; \\ hgkolev@gmail.com \\ * Correspondence: hbrunckova@saske.sk; Tel.: +421-55-7922-455
}

check for updates

Citation: Brunckova, H.; Mudra, E.; Rocha, L.; Nassar, E.; Nascimento, W.; Kolev, H.; Lisnichuk, M.; Kovalcikova, A.; Molcanova, Z.; Strečkova, M.; et al. Nanostructure and Luminescent Properties of Bimetallic Lanthanide $\mathrm{Eu} / \mathrm{Gd}, \mathrm{Tb} / \mathrm{Gd}$ and $\mathrm{Eu} / \mathrm{Tb}$ Coordination Polymers. Inorganics 2021, 9, 77. https://doi.org/10.3390/ inorganics 9100077

\section{Academic Editors:}

Lars Öhrström, Susan Bourne and Francoise M. Amombo Noa

Received: 6 September 2021

Accepted: 13 October 2021

Published: 15 October 2021

Publisher's Note: MDPI stays neutral with regard to jurisdictional claims in published maps and institutional affiliations.

Copyright: (c) 2021 by the authors. Licensee MDPI, Basel, Switzerland. This article is an open access article distributed under the terms and conditions of the Creative Commons Attribution (CC BY) license (https:// creativecommons.org/licenses/by/ $4.0 /)$.

\begin{abstract}
This study presents the synthesis, structural and luminescence properties for lanthanide metal-organic frameworks (LnMOFs), which belong to the sub-class of coordination polymers. The series of nanosized LnMOFs ( $\mathrm{Ln}=\mathrm{Eu}, \mathrm{Gd}, \mathrm{Tb}, \mathrm{Eu}_{0.5} \mathrm{Gd}_{0.5}, \mathrm{~Tb}_{0.5} \mathrm{Gd}_{0.5}$ and $\mathrm{Eu}_{0.5} \mathrm{~Tb}_{0.5}$ ) was prepared by solvothermal synthesis using a modulator (sodium acetate). We investigated the various surface chemistry compositions of the isostructural LnMOFs with a [Ln(btc)] structure (BTC: Benzene-1,3,5tricarboxylate) by X-ray photoelectron spectroscopy (XPS). The XPS confirmed the mixed-valent $\mathrm{Eu}^{3+}$ and $\mathrm{Eu}^{2+}$ compounds, and the presence of $\mathrm{Tb}$ in both +3 and +4 valence states, and one +3 valency of Gd. A nanostructure of mixed LnMOFs (EuGd, TbGd and EuTb) with a rod-like shape is related to luminescence properties. The MOFs (EuTb and EuGd) presented Comission Internationale de l'Éclairage (CIE) chromaticities of $\mathrm{x}=0.666$ and $\mathrm{y}=0.331$, and $\mathrm{x}=0.654$ and $\mathrm{y}=0.348$, respectively, in the red region. They were better than the values desired for use in commercial phosphors, which are $x=0.64$ and $y=0.35$. For $[\mathrm{Tb} / \mathrm{Gd}(\mathrm{btc})]$, the CIE coordinates were $\mathrm{x}=0.334$ and $\mathrm{y}=0.562$, presenting emissions in the green region. Bimetallic LnMOFs are very promising UV light sensors for biological applications.
\end{abstract}

Keywords: coordination polymers; metal-organic frameworks; lanthanides; solvothermal synthesis; X-ray photoelectron spectroscopy; luminescence

\section{Introduction}

Coordination polymers (CPs) are constructed of metal ions and bridging ligands that combine them into solid-state structures extending in one (1D), two (2D), or three dimensions (3D). Two- and three-dimensional CPs with potential voids are often designated as metal-organic frameworks (MOFs) [1-5]. MOFs are a well-recognized sort of attractive blended materials built from varied metal centers and multidentate organic ligands via coordination bonds [6]. MOFs are a remarkable type of porous materials because of their potential in many uses, such as gas absorption, molecular segregation, storage, optics and catalysts $[7,8]$. Lanthanide metal-organic frames (LnMOF) are recognized as specific types due to their special coordination characteristics and excellent optical properties resulting from $4 \mathrm{f}$ electrons [9]. LnMOFs are well known for their great Stokes' shifts, high color purity, and rather prolonged luminescence lifetimes outgoing from $\mathrm{f}$-f transitions trough the "antenna effect" $[9,10]$. LnMOFs display sharp and intense luminescence, emissions in the primal color scale (red, green and blue) that entirely cover the whole visible spectrum and therefore can be well combined for the design of white-light emitting materials [11]. Luminescent LnMOFs are now of great benefit and significance due their 
technical importance as sensors [6]. Trivalent lanthanides $\left(\mathrm{Ln}^{3+}\right)$ are an ideal selection, as the inorganic metal cation in the construction of nano-MOFs and Ln centers allows for multimodal imaging [12]. The trivalent ions of europium and terbium radiate intensive red and green light, respectively, while the $\mathrm{Gd}^{3+}$ complex emits in the blue zone due to its high lowest level of emitting $[10,13]$. As a result, varied lanthanide complexes $\left(\mathrm{Gd}^{3+}, \mathrm{Tb}^{3+}\right.$ and $\mathrm{Eu}^{3+}$ ) possess eventual applications in the creation of white-light emission [10].

Lanthanide MOFs built using coordination bonds among Ln ions and organic ligands are hopeful materials due to their porous crystalline structures, rich mixtures and simple preparation $[14,15]$. The set of $\operatorname{LnMOFs}[\mathrm{Ln}(\mathrm{btc})]$ was prepared by solvothermal synthesis via classical $\mathrm{H}_{3} \mathrm{BTC}$, and was used for the luminescence sensing of benzene homologue solutions [16]. [Eu(btc)] and [Tb(btc)] show acute and stark emissions in the visible light range. $[\mathrm{Eu}(\mathrm{btc})]$ was prepared by solvothermal synthesis using $\mathrm{N}, \mathrm{N}$-dimethylformamide (DMF) as the solvent, with modulator sodium acetate (NaOAc) $[6,16,17]$. In an effort to optimize the preparation requirements, the luminescent properties of $\left[\mathrm{Eu}(\mathrm{btc})\left(\mathrm{H}_{2} \mathrm{O}\right)(\mathrm{dmf})\right]$ with different morphologies, which show similar red light emissions and different intensities of short ultraviolet radiation, were investigated [6]. Ren et al. [18] studied the influence of the MOF size as sensors, and prepared bulk TbMOF and distinct sizes of nano-TbMOFs by the ultrasound-supported method via $\mathrm{NaOH}$ as a modulating agent, and demonstrated that these $[\mathrm{Tb}(\mathrm{btc})]$ have the same structure. Bimetallic MOF has two luminescence centers into this network, similarly to [Eu/Tb/(btc)] [17], [Eu/Gd(btc)] and [Tb/Gd(btc)] [10,12]. $\mathrm{The}[\mathrm{Eu} / \mathrm{Tb} /(\mathrm{btc})]$ emission color is orange-red [17] and $\mathrm{Eu} / \mathrm{GdMOF}$ results in strong red emissions [19]. The $[\operatorname{Ln}(\mathrm{btc})]$ sets were built with trivalent lanthanide $\left(\mathrm{Ce}^{3+}, \mathrm{Y}^{3+}\right.$, or a combination thereof) [8]. Heterometallic Eu/Tb-MOF exhibits luminescence, and was obtained by solvothermal synthesis with various ligands, such as 2-phenylsuccinate (psa) [20], 4,4'-oxybis(benzoate) acid ( $\left.\mathrm{H}_{2} \mathrm{OBA}\right)$ [21], furan-2,5-dicarboxylic acid $\left(\mathrm{H}_{2} \mathrm{FDA}\right)$ [22] and 1,3-bis (3,5-dicarboxyphenyl) imidazolium chloride $\left(\mathrm{H}_{4} \mathrm{~L}^{+} \mathrm{Cl}^{-}\right)$[23]. A series of hybrid LnMOFs as $\left[\mathrm{Eu}_{\mathrm{x}} \mathrm{Gd}_{1-\mathrm{x}}(\mathrm{ndc})\right]\left(\mathrm{x}=0.0005-0.01 ; \mathrm{H}_{2} \mathrm{NDC}=1\right.$,4-naphthalene dicarboxylic acid) using aback power transmission were fabricated for the physiologic sensing of the temperature [24].

The aim of the work was to characterize the chemical content, binding structures and morphologies on the surface of the LnMOF series $(\mathrm{Ln}=\mathrm{Eu}, \mathrm{Gd}, \mathrm{Tb})$ and mixed $\left(\mathrm{Ln}=\mathrm{Eu}_{0.5} \mathrm{Gd}_{0.5}, \mathrm{~Tb}_{0.5} \mathrm{Gd}_{0.5}\right.$ and $\left.\mathrm{Eu}_{0.5} \mathrm{~Tb}_{0.5}\right)$ prepared by solvothermal synthesis using $\mathrm{DMF} / \mathrm{H}_{2} \mathrm{O}$ solution and adding sodium acetate as modulator. Moreover, the effect of mixed different bimetallic lanthanides in $\left[\mathrm{Ln}(\mathrm{btc})(\mathrm{dmf})\left(\mathrm{H}_{2} \mathrm{O}\right)\right]$ nanostructures on the surface chemistry composition was studied. The novelty of this research is the TEM characterization of different nanostructures of bimetallic LnMOFs. The luminescence property of fabricated bimetallic LnMOFs were explored. Luminescence spectra presented high excitation bands and intense emissions. The resulting luminescent LnMOFs can be applied in the production of various optical equipment.

\section{Materials and Methods}

\subsection{Materials and Chemicals}

All of the chemical agents and dissolvents were purchased from Sigma-Aldrich at analytical grade and applied without another purgation. Europium(III) nitrate hydrate $\mathrm{Eu}\left(\mathrm{NO}_{3}\right)_{3} \cdot 5 \mathrm{H}_{2} \mathrm{O}$, gadolinium(III) nitrate hydrate $\mathrm{Gd}\left(\mathrm{NO}_{3}\right)_{3} \cdot 6 \mathrm{H}_{2} \mathrm{O}$, terbium(III) nitrate hydrate $\mathrm{Tb}\left(\mathrm{NO}_{3}\right)_{3} \cdot 6 \mathrm{H}_{2} \mathrm{O}, \mathrm{N}, \mathrm{N}$-dimethylformamide (DMF), 1,3,5-benzenetricarboxylic acid (BTC), sodium acetate $(\mathrm{NaOAc})$ and deionized water were availed to the solvothermal synthesis.

\subsection{Preparation of the $\mathrm{LnMOFs}$}

The LnMOFs were prepared via modified solvothermal synthesis $[6,16,17]$ pursuant to the previous work [25]. Lanthanide(III) nitrate hydrate $\mathrm{Ln}\left(\mathrm{NO}_{3}\right)_{3} \cdot \mathrm{xH}_{2} \mathrm{O}(1.0 \mathrm{mmol})$ and $\mathrm{H}_{3} \mathrm{BTC}(0.21 \mathrm{~g}, 1.0 \mathrm{mmol})$ were dissolved in a $30 \mathrm{~mL}$ mixture of $\mathrm{DMF} / \mathrm{H}_{2} \mathrm{O}(1: 1 \mathrm{v} / \mathrm{v})$ solvents $(\mathrm{Ln}=\mathrm{Eu}, \mathrm{Gd}, \mathrm{Tb})$ together with the modulator $\mathrm{NaOAc}(0.3 \mathrm{mmol})$. The preparation procedures for the $\mathrm{Eu}, \mathrm{Gd}$ and $\mathrm{Tb}$ lanthanide MOFs were the same, and were performed 
using different starting nitrates using $\mathrm{Eu}\left(\mathrm{NO}_{3}\right)_{3} \cdot 5 \mathrm{H}_{2} \mathrm{O}(0.443 \mathrm{~g}), \mathrm{Gd}\left(\mathrm{NO}_{3}\right)_{3} \cdot 6 \mathrm{H}_{2} \mathrm{O}(0.448 \mathrm{~g})$ and $\mathrm{Tb}\left(\mathrm{NO}_{3}\right)_{3} .5 \mathrm{H}_{2} \mathrm{O}(0.449 \mathrm{~g})$. The ratio of Ln:TBC was 0.36 . The three solutions of $[\mathrm{Eu}(\mathrm{btc})](\mathrm{Eu}-1),[\mathrm{Gd}(\mathrm{btc})](\mathrm{Gd}-2)$ and $[\mathrm{Tb}(\mathrm{btc})](\mathrm{Tb}-3)$ were mixed at $25{ }^{\circ} \mathrm{C}$ for $1 \mathrm{~h}$ and heated at $60{ }^{\circ} \mathrm{C}$ for $48 \mathrm{~h}$, and then cooled to room temperature to give white (Eu-1 and Gd-2) and colorless (Tb-3) crystals. After the synthesis, the products were isolated by centrifugation and washed several times with ethanol and water, respectively, and then dried in air. The prepared Eu-1, Gd-2 and Tb-3 resulted in a yield of $66 \%(0.319 \mathrm{~g}), 69 \%$ $(0.270 \mathrm{~g})$ and $70 \%(0.339 \mathrm{~g})$, respectively, without elemental analysis. The preparation of the mixed bimetallic $\left[\mathrm{Eu}_{0.5} \mathrm{Gd}_{0.5}(\mathrm{btc})\right](\mathrm{EuGd}-4),\left[\mathrm{Tb}_{0.5} \mathrm{Gd}_{0.5}(\mathrm{btc})\right](\mathrm{TbGd}-5)$ and $\left.\mathrm{Eu}_{0.5} \mathrm{~Tb}_{0.5}(\mathrm{btc})\right]$ $(\mathrm{EuTb}-6)$ was the same as that for simple [Ln(btc)], only the pure Ln nitrate was exchanged via a mixture of two corresponding nitrates. For the preparation of the EuGd-4 powder, the nitrate of Eu $(0.223 \mathrm{~g}, 0.5 \mathrm{mmol})$ and $\mathrm{Gd}(0.224 \mathrm{~g}, 0.5 \mathrm{mmol})$ with BTC $(0.21 \mathrm{~g}, 1.0 \mathrm{mmol})$ and NaOAc $(0.03 \mathrm{~g}, 0.3 \mathrm{mmol})$ was dissolved in $30 \mathrm{~mL} \mathrm{DMF} / \mathrm{H}_{2} \mathrm{O}$. For TbGd-5 or EuTb-6 syntheses were used $\mathrm{Tb}\left(\mathrm{NO}_{3}\right)_{3} \cdot 6 \mathrm{H}_{2} \mathrm{O}(0.225 \mathrm{~g}$, $0.5 \mathrm{mmol})$ separately. The bimetallic LnMOF powders were formed after heating at $60^{\circ} \mathrm{C}$ for $48 \mathrm{~h}$. The preparation procedures for the other lanthanide MOFs were analogous. The experimental synthesis of each sample was repeated three times. The syntheses of $\mathrm{Tb}-3$ and $\mathrm{TbGd}-5 \mathrm{MOF}$ were performed without the NaOAc modulator for the SEM and TEM analysis.

The comparison with the other methods and procedures for solvothermal synthesis of $\operatorname{LnBTC}\left(\mathrm{Ln}=\mathrm{Eu}_{0.5} / \mathrm{Gd}_{0.5}\right.$ or $\left.\mathrm{Tb}_{0.5} / \mathrm{Gd}_{0.5}\right)$ used the selected lanthanide chloride salts, sodium trifluoroacetate (NaTFA), and BTC in a 1:0.9:0.6 Ln:TFA:BTC ratio, with the solvents water and DMF [12] and a ball milling preparation of $\left[\mathrm{Eu}_{0.5} / \mathrm{Gd}_{0.5}(\mathrm{btc})\right]$ or $\left[\mathrm{Tb}_{0.5} / \mathrm{Gd}_{0.5}(\mathrm{btc})\right]$ with the $\mathrm{H}_{3} \mathrm{BTC}$ and the respective lanthanide carbonate hydrates $\mathrm{Ln}_{2}\left(\mathrm{CO}_{3}\right)_{3} \cdot \mathrm{xH}_{2} \mathrm{O}$ in a 2:1 molar ratio. The other solvothermal syntheses of LnMOFs have been reported with various ligands, such as psa [20], $\mathrm{H}_{2} \mathrm{OBA}$ [21], $\mathrm{H}_{2}$ FDA acid [22], $\mathrm{H}_{4} \mathrm{~L}^{+} \mathrm{Cl}^{-}$[23] and NDC [24].

\subsection{Characterization of the LnMOFs}

The FTIR analysis of the LnMOF compounds was performed using the FTIR spectrometer Shimadzu IRAffinity1 (KBr pellets). The composition and structure of the samples were obtained using an X-ray diffraction (XRD) instrument ( $X^{\prime}$ Pert Pro, Philips, Amsterdam, The Netherlands) via $\mathrm{Cu} \mathrm{K} \alpha$ radiation. The surface morphologies were characterized using scanning electron microscopy (SEM) (Auriga Compact, Carl Zeiss, Jena, Germany) and high resolution transmission electron microscopy (TEM), (JEOL-JEM 2100F), using a scanning transmission electron microscope (STEM) and energy dispersive X-ray (EDS, Oxford Energy TEM 250) spectroscopy. The additional composition and valence state inquiry were obtained by X-ray photoelectron spectroscopy (XPS). The energy range was scaled using a standardizing $\mathrm{C}$ 1s line of acquired hydrocarbons to $285.0 \mathrm{eV}$ for the electrostatical sample. The luminescence spectra were characterized at room temperature, using a continuous Xenon lamp or a flash Xenon lamp in a Horiba Jobin Yvon Fluorolog-3 spectrofluorimeter equipped with a double excitation monochromator and a single emission monochromator. The excitation and emission spectra were obtained at various emission and excitation wavelengths, respectively.

\section{Results and Discussion}

\subsection{Structural Characterization of the LnMOFs}

The TG and DSC curves of LnMOFs (Eu-1, Gd-2, Tb-3) prepared by sovothermal synthesis using the modulator $(\mathrm{NaOc})$ are shown in Figure 1 . The TG curves are similar, and all of them display a two-step or three-step weight loss [6]. The initial weight lossstarting at around $100^{\circ} \mathrm{C}$ and continuing up to $160{ }^{\circ} \mathrm{C}$-observed for all of the samples can be ascribed to the loss of coordinated solvent molecules (DMF and $\mathrm{H}_{2} \mathrm{O}$ ) [25]. The TG curves of Eu-1and Gd-2 show the two main steps of gradual weight loss process before $220{ }^{\circ} \mathrm{C}$, attributed to the release of $\mathrm{H}_{2} \mathrm{O}$ and two DMF molecules, and $7.0 \%$ in $220-410{ }^{\circ} \mathrm{C}$ temperature range, corresponding to the loss of coordinated DMF molecules. Above $410{ }^{\circ} \mathrm{C}$, the complete framework sequentially begins to collapse upon further heating. All 
of the samples had similar thermal stability up to $540-600{ }^{\circ} \mathrm{C}$. The weight loss at higher temperatures of $540-600{ }^{\circ} \mathrm{C}$ was attributed to the thermal decomposition of [Ln(BTC)] to Ln oxides. The DSC curves result show that the end point of the endo peak depends on chemical component of the lanthanides (Eu-1: $620^{\circ} \mathrm{C}, \mathrm{Gd}-2: 658^{\circ} \mathrm{C}$ and $\left.\mathrm{Tb}-3: 673{ }^{\circ} \mathrm{C}\right)$.

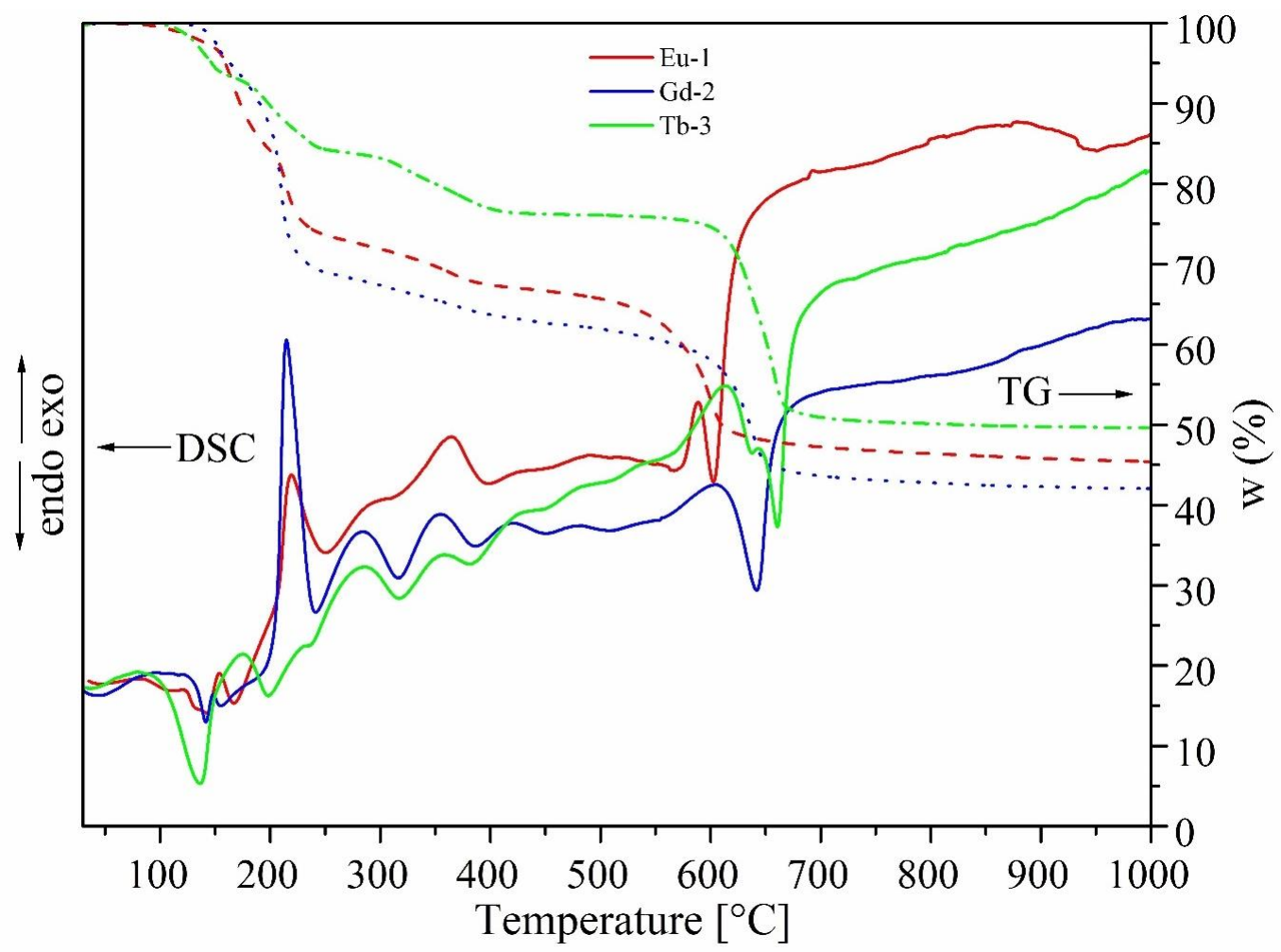

Figure 1. DSC/TG curves of $\operatorname{LnMOF}(\mathrm{Ln}=\mathrm{Eu}, \mathrm{Gd}, \mathrm{Tb})$ prepared by solvothermal synthesis.

Figure S1 presents the FTIR spectra of LnMOF isostructural compounds prepared using solvothermal synthesis [25]. The wide peak at $3420 \mathrm{~cm}^{-1}$ is assigned to $v(\mathrm{O}-\mathrm{H})$ groups. The effect of acetate groups from sodium acetate can be noticed in the regions at 2983,2786 and $2441 \mathrm{~cm}^{-1}$, which are assigned to stretching $v(\mathrm{C}-\mathrm{H})$ vibrations. In the spectrum of $\mathrm{H}_{3}$ BTC acid, the characteristic bands of the carboxyl group of BTC are at 3090, 1720 , and $537 \mathrm{~cm}^{-1}$. In the spectra of MOFs, no band at $1720 \mathrm{~cm}^{-1}$ corresponding to the $\mathrm{COOH}$ groups can be seen, designating the complete deprotonation of the carboxylic acid and coordination of $\mathrm{COO}^{-}$groups to the lanthanide centre. The peak at $1678 \mathrm{~cm}^{-1}$ belongs to $v(\mathrm{C}=\mathrm{O})$ of DMF. In the spectra, the bands in the zones of $1568-1538 \mathrm{~cm}^{-1}$ and $1386 \mathrm{~cm}^{-1}$ were marked as stretching vibrations of the $\mathrm{COO}^{-}$groups $v_{\mathrm{as}}$ and $v_{\mathrm{s}}$, respectively. The powerful peaks provide the $\mathrm{C}-\mathrm{H}$ bending benzene vibrations that shifted to the region of 775 and $710 \mathrm{~cm}^{-1}[8,26]$. The peak which appeared at $563 \mathrm{~cm}^{-1}$ can be assigned to the stretching vibration of $\mathrm{Eu}, \mathrm{Gd}$ and $\mathrm{Tb}-\mathrm{O}[1,27]$. The structural designation of the LnMOFs is marked as $\left[\mathrm{Ln}(\mathrm{btc})\left(\mathrm{H}_{2} \mathrm{O}\right)(\mathrm{dmf})\right][6,9,25]$.

The XRD diffractograms of the samples are shown in Figure S2. The XRD peaks are in good compliance with previous report indicating that the obtained MOFs are isostructural [25]. The XRD diffractograms are in good agreement with patterns of [Ln(btc)], which have a tetragonal structure, as [La(btc)] simulated [28]. The diffraction patterns indicate the formation of $[\mathrm{Ln}(\mathrm{btc})],\left(\mathrm{Ln}=\mathrm{Eu}, \mathrm{Gd}, \mathrm{Tb}, \mathrm{Eu}_{0.5} \mathrm{Gd}_{0.5}, \mathrm{~Tb}_{0.5} \mathrm{Gd}_{0.5}\right.$ and $\left.\mathrm{Eu}_{0.5} \mathrm{~Tb}_{0.5}\right)$ in $2 \theta$ of $10.5^{\circ}, 18.3^{\circ}, 20.3^{\circ}, 27.5^{\circ}$ and $32^{\circ}$ of the most important peaks $[25,28]$. The other peaks also match the $[\mathrm{La}(\mathrm{btc})]$ structure. The $\left[\mathrm{Eu}(\mathrm{btc})\left(\mathrm{H}_{2} \mathrm{O}\right)(\mathrm{dmf})\right]$, built with a $\mathrm{Eu}^{3+}$ cation and the organic linker BTC via coordination bonding, is a 3D framework with a tetragonal structure $[6,9,16]$. XRD showed that the $\left[\mathrm{Eu}(\mathrm{btc})\left(\mathrm{H}_{2} \mathrm{O}\right)(\mathrm{dmf})\right]$ structure is not changed using a slight addition of $\mathrm{NaOAc}$, but it will be transformed to a monoclinic structure with the effect of a major quantity of modulator agent $[6,8]$. 


\subsection{XPS Characterization on the Surface of the LnMOF}

The XPS survey spectra of the samples are presented in Figure S3, with all of the peaks congruent to the typical electronic $\mathrm{Eu}, \mathrm{Gd}, \mathrm{Tb}, \mathrm{C}, \mathrm{O}$ and $\mathrm{N}$ transitions. The total concentration of the elements in the atomic percentage on the surface of the powders was obtained. The composition of the powders on the surface was determined from the intensities of the signals, and is summarized in Table S1. The relative atomic concentration of $\mathrm{Eu}, \mathrm{Gd}$ and $\mathrm{Tb}$ on the surface of the Eu-1 (5.9 at.\%), Gd-2 (4.1 at.\%) and Tb-3 (3.8 at.\%) MOFs was higher than mixed EuGd-4 (2.5 at.\%), TbGd-5 (1.9 at.\%) and EuTb (2.0 at.\%), respectively. The surface composition for EuTb-6 in at.\% of Eu, Tb, C, O and $\mathrm{N}$ was determined as 1.8, 2.0, 53.7, 33.8 and 8.7, respectively. The values calculated for the assumed formulae of $\left[\mathrm{Ln}(\mathrm{btc})(\mathrm{dmf})_{2}\left(\mathrm{H}_{2} \mathrm{O}\right)\right],\left\{\mathrm{Ln}\left[\mathrm{C}_{6} \mathrm{H}_{3}\left(\mathrm{CO}_{2}\right)_{3}\right]\left(\mathrm{C}_{3} \mathrm{H}_{7} \mathrm{NO}\right)_{2}\left(\mathrm{H}_{2} \mathrm{O}\right)\right.$, and $\mathrm{C}_{15} \mathrm{H}_{19} \mathrm{~N}_{2} \mathrm{O}_{9}$ Ln are $\mathrm{C}_{7} \mathrm{H}_{\mathrm{x}} \mathrm{N}_{2} \mathrm{O}_{7} \mathrm{Eu}, \mathrm{C}_{11.6} \mathrm{H}_{\mathrm{x}} \mathrm{N}_{2.8} \mathrm{O}_{9} \mathrm{Gd}, \mathrm{C}_{12.4} \mathrm{H}_{\mathrm{x}} \mathrm{N}_{3.5} \mathrm{O}_{9.4} \mathrm{~Tb}, \mathrm{C}_{10.8} \mathrm{H}_{\mathrm{x}} \mathrm{N}_{1.4} \mathrm{O}_{7.6}$ $\mathrm{Eu}_{0.52} \mathrm{Gd}_{0.48}, \mathrm{C}_{14.1} \mathrm{H}_{\mathrm{x}} \mathrm{N}_{2.6} \mathrm{O}_{10.6} \mathrm{~Tb}_{0.47} \mathrm{Gd}_{0.53}$ and $\mathrm{C}_{14.1} \mathrm{H}_{\mathrm{x}} \mathrm{N}_{2.3} \mathrm{O}_{8.9} \mathrm{Eu}_{0.47} \mathrm{~Tb}_{0.53}$.

In Figure 2, the high resolution HR XPS Eu 3d, Gd 3d, Tb 3d and C 1s, O 1s and N 1s spectra of [Ln(btc)] powders can be observed. The XPS Eu 3d spectrum of Eu-1, EuGd-4 and EuTb- 6 contains two significant peaks at $1135 \mathrm{eV}\left(\mathrm{Eu}^{3+} 3 \mathrm{~d}_{5 / 2}\right)$ and $1165 \mathrm{eV}\left(\mathrm{Eu}^{3+} 3 \mathrm{~d}_{3 / 2}\right)$ binding energies, together with two minor satellites that appear at $1128 \mathrm{eV}\left(\mathrm{Eu}^{2+} 3 \mathrm{~d}_{5 / 2}\right)$ and $1155 \mathrm{eV}\left(\mathrm{Eu}^{2+} 3 \mathrm{~d}_{3 / 2}\right)[10,29]$. The XPS spectrum of Gd-2, EuGd-4 and Tb-Gd-5 shows

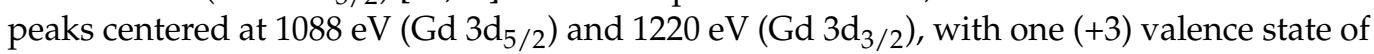
gadolinium. The XPS Tb 3d spectrum for the Tb-3, TbGd-5 and EuTb-6 samples represents two peaks at 1242 and $1277 \mathrm{eV}$, assigned to $3 \mathrm{~d}_{5 / 2}$ and $3 \mathrm{~d}_{3 / 2}$ of $\mathrm{Tb}^{3+}$, respectively. The presence of $\mathrm{Tb}^{4+}$ was found in a small peak at $1250 \mathrm{eV}[10,14,30,31]$. XPS corroborated the coordination impact among europium, gadolinium and terbium ions and the BTC ligand. The XPS spectrum of $\mathrm{O} 1 \mathrm{~s}, \mathrm{C} 1 \mathrm{~s}$ and $\mathrm{N} 1 \mathrm{~s}$ in all of the LnMOF powders showed peaks centered at 532, 285 and $402-407 \mathrm{eV}$, respectively.
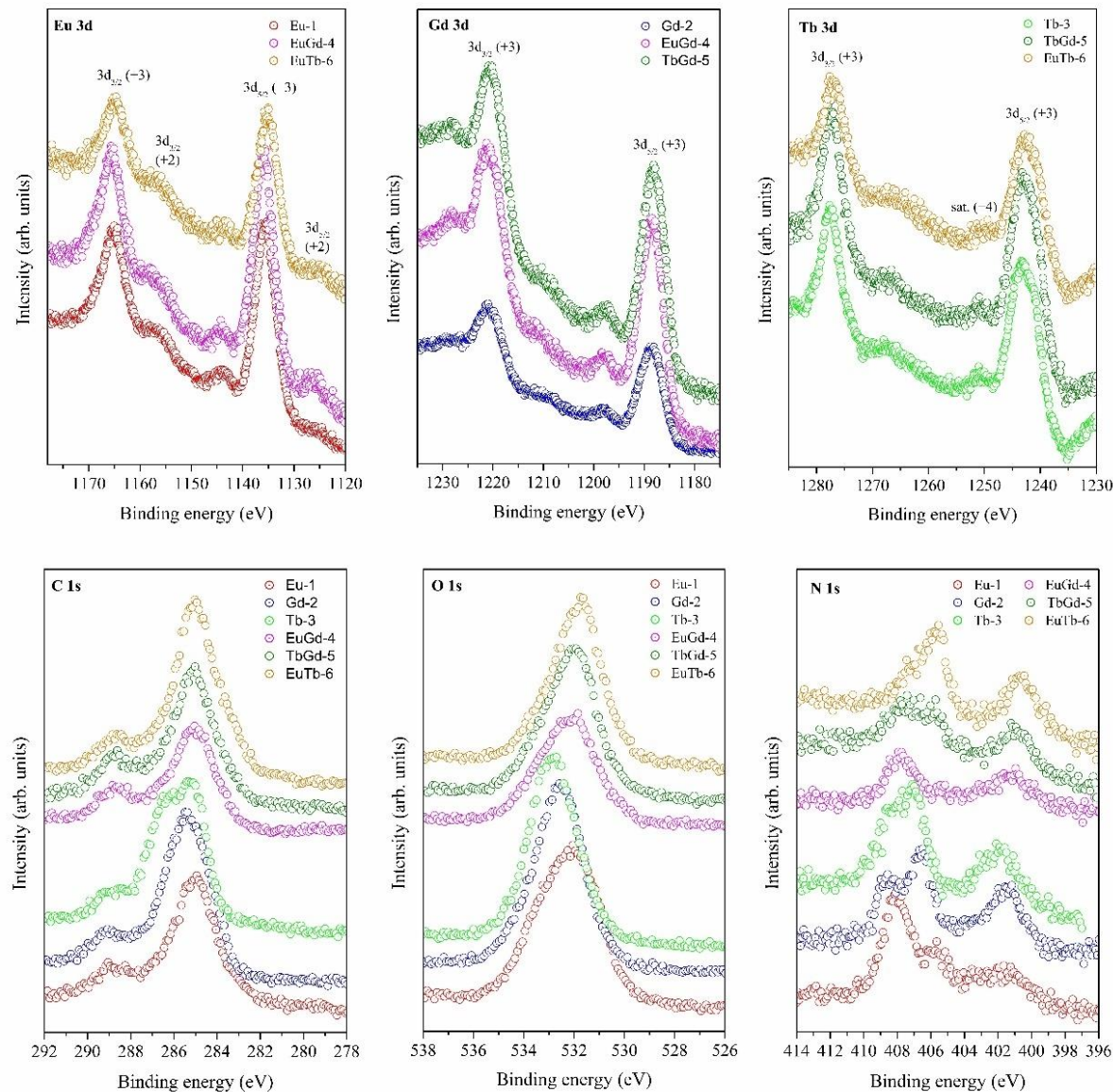

Figure 2. HR XPS spectra of the Eu 3d, Gd 3d, Tb 3d, C 1s, O 1s and N 1s of [Ln(btc)] (Eu-1, Gd-2, Tb-3, EuGd-4, TbGd-5 and EuTb-6) powders. 
In Figure S4, XPS presents evidence of the attendance of two valency states for $\mathrm{Eu}\left(\mathrm{Eu}^{3+} / \mathrm{Eu}^{2+}\right)$ and $\mathrm{Tb}\left(\mathrm{Tb}^{3+} / \mathrm{Tb}^{4+}\right)$ at the surface of the MOFs. In the $[\mathrm{Eu}(\mathrm{btc})]$ and $\left[\mathrm{Eu}_{0.5} \mathrm{~Tb}_{0.5}(\mathrm{btc})\right](\mathrm{MOFs})$, the $\mathrm{Eu}^{3+}$ and $\mathrm{Eu}^{2+}$ valency states were noticed at 135 and $130 \mathrm{eV}$, respectively. The states of $\mathrm{Tb}^{3+}$ and $\mathrm{Tb}^{4+}$ in $[\mathrm{Tb}(\mathrm{btc})],\left[\mathrm{Tb}_{0.5} \mathrm{Gd}_{0.5}(\mathrm{btc})\right]$ and $\left[\mathrm{Eu}_{0.5} \mathrm{~Tb}_{0.5}(\mathrm{btc})\right]$ were confirmed. The spectrum of $\mathrm{Tb} 4 \mathrm{~d}$ acquired for the Tb-3 and EuTb-6 sample shows a strong peak at $150 \mathrm{eV}$ and a small peak at $155 \mathrm{eV}$, attributed $\mathrm{Tb}^{3+}$ and $\mathrm{Tb}^{4+}$, respectively. The $\mathrm{Eu}^{2+}$ concentration of Eu- 1 and EuTb- 6 was detected to be 0.8 and 0.1 at.\%. In the Tb-3 and EuTb-6 samples, the $\mathrm{Tb}^{4+}$ amount was determined to be 0.2 and 0.1 at.\%. The presence of the two valence states, $\mathrm{Eu}^{3+} / \mathrm{Eu}^{2+}$ and $\mathrm{Tb}^{3+} / \mathrm{Tb}^{4+}$, in the corresponding samples was confirmed. This could also be caused by the preparation of samples and drying in air.

The XPS core-level spectra of the O 1s, C 1s and N 1s of Eu-1 and EuTb-6 are shown in Figure 3. The total atomic percentage concentrations of $\mathrm{C}, \mathrm{O}$ and $\mathrm{N}$ in the EuTb-6 powder on the surface were determined to be 53.7, 33.8 and $8.7 \%$, respectively. The $C 1$ s peak for EuTb- 6 can be sectioned into three peaks at $285.0,286.8$ and $288.9 \mathrm{eV}$, which were assigned to C-H, C-C (35.4 at.\%), C-O, C-O-H (8.2 at.\%) and C=O. C-O-C (10.1 at.\%), respectively [32,33]. The $\mathrm{O} 1 \mathrm{~s}$ peak can be composed of three peaks at 531.3, 531.8 and $533.1 \mathrm{eV}$, which were ascribed to C-O (8.8 at.\%), H-C-O (17.2 at.\%) and O-H, with Ln-C-O (7.8 at.\%) bindings of EuTb-6 $[33,34]$. The N 1s peak of the EuTb-6 sample, as shown in Figure 3, contains three peaks assigned to the subsequent bands: $400.6 \mathrm{eV}(\mathrm{N}-\mathrm{H}-\mathrm{N}-\mathrm{O}, \mathrm{C}-\mathrm{H}-\mathrm{OH}), 405.6 \mathrm{eV}(\mathrm{N}-\mathrm{O})$, and $407.2 \mathrm{eV}(\mathrm{O}-\mathrm{N}-\mathrm{C}-\mathrm{H})[34,35]$. The XPS results for $\mathrm{C} 1 \mathrm{~s}$ and $\mathrm{N}$ 1s are in good agreement with the FTIR $v(\mathrm{C}=\mathrm{O})$ and $\delta(\mathrm{O}=\mathrm{C}-\mathrm{N})$ from coordinated DMF, respectively.
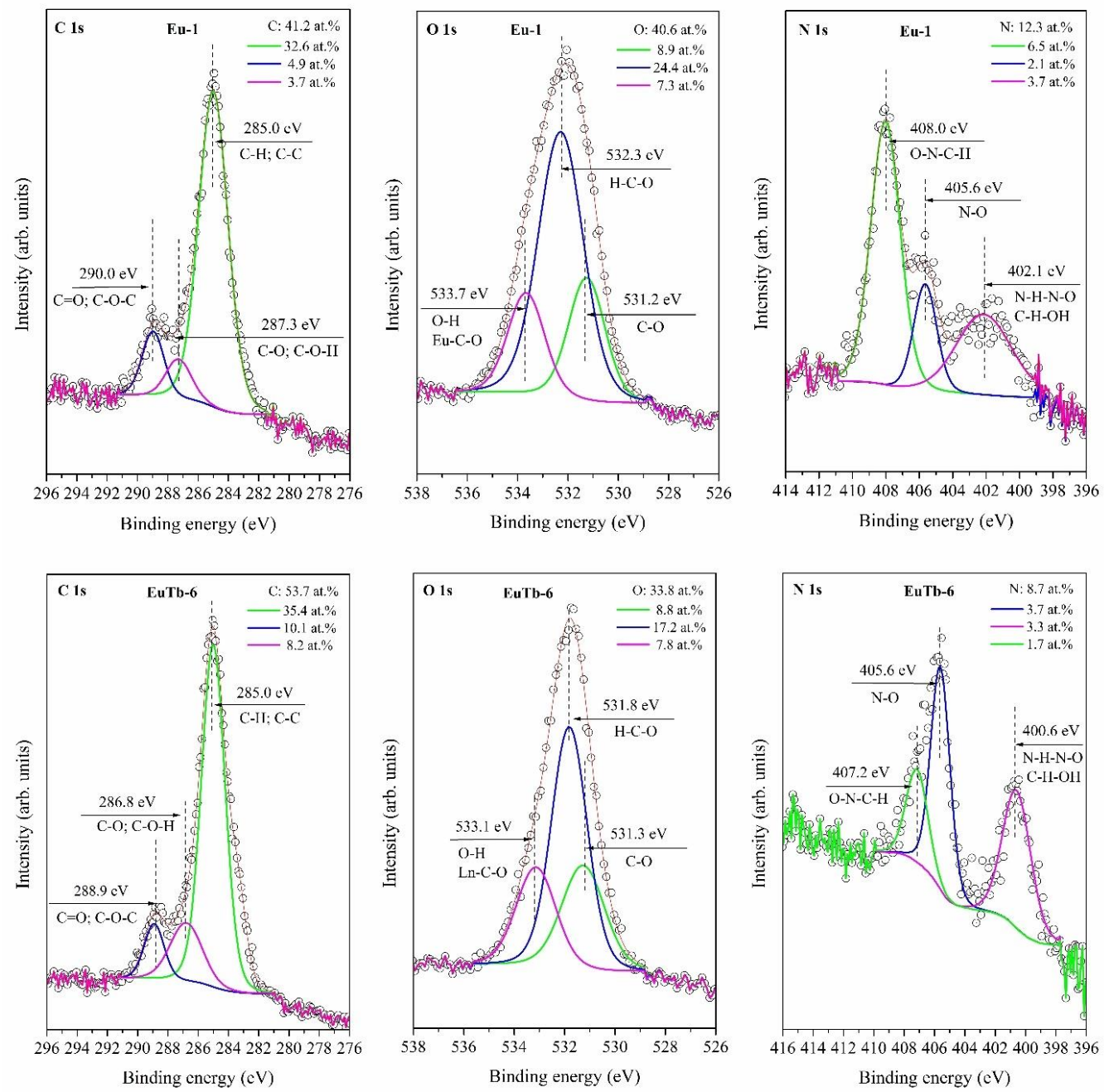

Figure 3. HR XPS spectra of $\mathrm{C} 1 \mathrm{~s}, \mathrm{O} 1 \mathrm{~s}$ and $\mathrm{N} 1 \mathrm{~s}$, and curve-fitted peaks for [Eu(btc)] and $\left[\mathrm{Eu}_{0.5} \mathrm{~Tb}_{0.5}(\mathrm{btc})\right]$ powders. 


\subsection{Surface Morphologies of LnMOFs}

The surface morphology of the as-synthesized powders was characterized using SEM and TEM. The images of the SEM and EDS analysis of LnMOF in Tb-3, TbGd-5 and EuTb-6 (insert TEM images) are shown in Figure S5 and Figure 4. The TbMOF morphology formed typical rods in the range of 2 to $10 \mu \mathrm{m}$ without a modulator (Figure S5a [15]. In Figure $\mathrm{S} 5 \mathrm{~b}$, needle-shaped nanocrystals of TbMOF after the addition of the modulator NaOAc can be observed [18]. The EDS spectra (Figure S5c,d) of [Tb(btc)] disclosed the presence of $\mathrm{C}, \mathrm{O}, \mathrm{N}$ and $\mathrm{Tb}$ elements in at.\% [36]. The EDS spectra of [ $\mathrm{Tb}(\mathrm{btc})]$ confirmed that the large rods and nano-rods possess equal molar ratios of $\mathrm{C}, \mathrm{O}, \mathrm{N}$ and $\mathrm{Tb}$ [6]. Similarly, the crystals of the TbGd-5 (Figure 4a) are evenly spaced, and form pillar-like rods with a size of 10-30 $\mu \mathrm{m}$ (without a modulator). In the EuTb-6 sample (synthetized using the modulator $\mathrm{NaOac}$ ), well-distributed nano-rods were observed (Figure 4c). The EDS spectra are shown in Figure $4 b, d$. The elements are compliant with the composition of the required LnMOF $\left\{\left[\mathrm{Tb}_{0.5} \mathrm{Gd}_{0.5}(\mathrm{btc})\right]\right.$ and $\left.\left[\mathrm{Eu}_{0.5} \mathrm{~b}_{0.5}(\mathrm{btc})\right]\right\}$ structures.
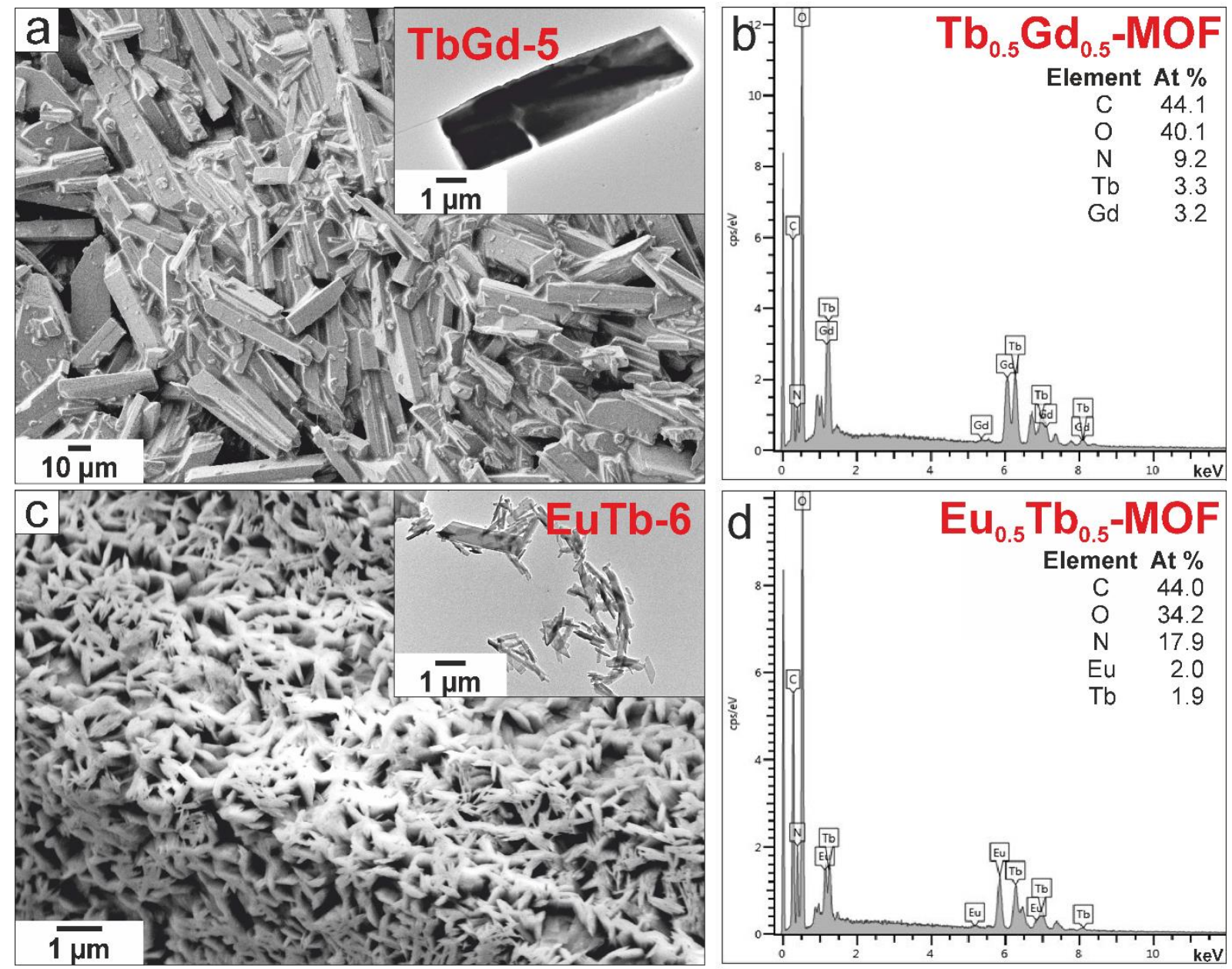

Figure 4. SEM morphology and TEM images (in insert) of LnMOF powders prepared by the solvothermal synthesis of (a) TbGd-5 (DMF/ $\left.\mathrm{H}_{2} \mathrm{O}\right)$ and (c) EuTb-6 (DMF/ $\left.\mathrm{H}_{2} \mathrm{O} / \mathrm{NaOAc}\right)$; and the EDS spectra of (b) $\left[\mathrm{Tb}_{0.5} \mathrm{Gd}_{0.5}(\mathrm{btc})\right]$ and (d) $\left[\mathrm{Eu}_{0.5} \mathrm{~Tb}_{0.5}(\mathrm{btc})\right]$.

The TEM micrographs of the Eu- $1, \mathrm{Gd}-2$ and Tb-3 samples and the hybrid MOF (EuGd-4, TbGd-5, and EuTb-6) are displayed in Figure 5. It is absorbing to comment that all of the LnMOF samples prepared using the modulator $\mathrm{NaOc}$ exhibit a uniform morphology of their rods, with a size of 100-400 nm [11]. Figure $5 \mathrm{~d}$ presents one rod with a length of $850 \mathrm{~nm}$ and a width of $400 \mathrm{~nm}$, within which small nanorods (length 300-450 nm and width 50-100 nm) are incorporated. In Table 1, the variation of the lanthanide in the LnMOFs results in quite uniform rod-like nanocrystals with a length and width of 
$850 \mathrm{~nm}$ and $400 \mathrm{~nm}$, respectively (EuGd-4), included smaller particles with a length of $300 \mathrm{~nm}$ and a width of $50 \mathrm{~nm}$. The size of the nanorods decreases in this order: EuGd-4, TbGd-5 and EuTb-6. The records acquired using TEM were fully alike and agreed well with the results of samples prepared using solvothermal synthesis with the addition of a modulator $(\mathrm{NaOAc})$ gained from SEM. The various SEM and TEM morphologies of the bimetallic [ $\mathrm{Ln}(\mathrm{btc})]\left(\mathrm{Eu}_{0.5} \mathrm{Gd}_{0.5}, \mathrm{Gd}_{0.5} \mathrm{~Tb}_{0.5}\right.$ and $\left.\mathrm{Eu}_{0.5} \mathrm{~Tb}_{0.5}\right)$ were changed depending on the synthesis chemistry composition of the $\mathrm{Ln}^{3+}$ ions from the nanorods $(100-300 \mathrm{~nm}$ ) for $\left[\mathrm{Eu}_{0.5} \mathrm{Gd}_{0.5}(\mathrm{btc})\right]$ and $\left[\mathrm{Gd}_{0.5} \mathrm{~Tb}_{0.5}(\mathrm{btc})\right]$ to nanoparticles $(20-100 \mathrm{~nm})$ for $\left[\mathrm{Eu}_{0.5} \mathrm{~Tb}_{0.5}(\mathrm{BTC})\right]$.

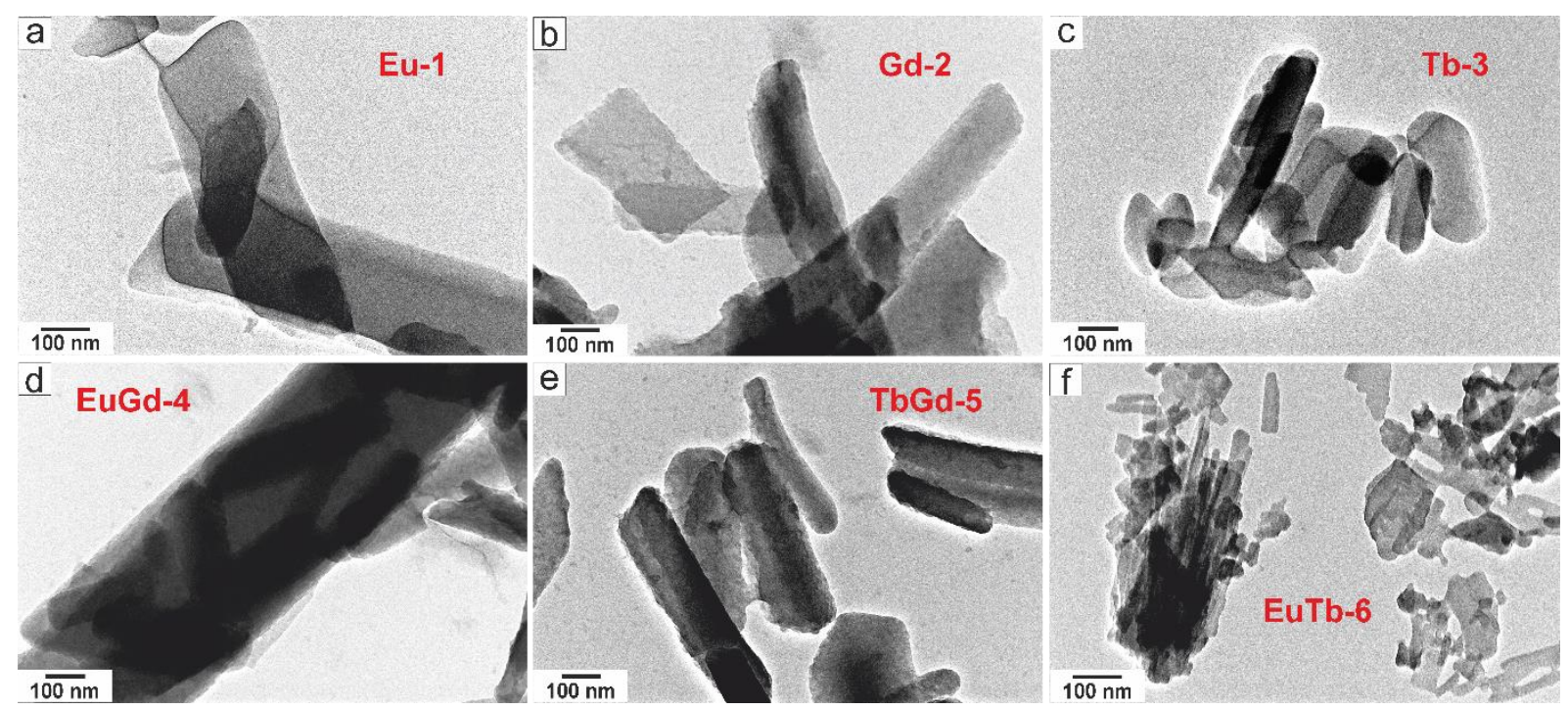

Figure 5. TEM images of the LnMOF powders: (a) Eu-1, (b) Gd-2, (c) Tb-3, (d) EuGd-4, (e) TbGd-5 and (f) EuTb-6.

Table 1. The variation in sizes of the nanorods obtained from the TEM images (Figure 5).

\begin{tabular}{ccccc}
\hline \multirow{2}{*}{ LnMOF } & \multicolumn{2}{c}{ Size of Nanorod $(\mathbf{n m})$} & \multicolumn{2}{c}{ Size of Included Particles (nm) } \\
\cline { 2 - 5 } & Length & Width & Length & Width \\
\hline \multirow{2}{*}{ Eu-1 } & 820 & 280 & 350 & 100 \\
& 600 & 150 & 200 & 50 \\
Gd-2 & 730 & 150 & 150 & 50 \\
& 600 & 150 & 100 & 40 \\
Tb-3 & 400 & 50 & 150 & 60 \\
& 250 & 50 & 100 & 50 \\
EuGd-4 & 850 & & 450 & 50 \\
& 400 & 300 & 30 \\
TbGd-5 & 400 & 150 & 150 & 20 \\
& 300 & 30 & 130 & 20 \\
EuTb-6 & 140 & 20 & 40 & 20 \\
\hline
\end{tabular}

The STEM and EDS mapping of the elements in the LnMOFs (Figure 6) elucidate the homogeneous partition of the Ln, $\mathrm{O}$ and $\mathrm{C}$ elements through the surface of the samples [37]. The STEM images and EDS mapping (Figure 6a) of TbMOF further detected the presence of $\mathrm{Tb}, \mathrm{O}$ and $\mathrm{C}$ as incorporated elements in the respective particles [35]. In Figure $6 \mathrm{~b}-\mathrm{d}$, at different magnifications, are shown the nanorods of mixed EuGd-4, TbGd-5 and EuTb-6, respectively. The concentration of the elements (in at.\%) from the EDS spectra and the mapping of the Tb-3, EuGd-4, TbGd-5 and EuTb-6 samples from the STEM/EDS are summarized in Table S2. The elemental proportions on the surface of the LnMOFs are distinct from the bulk content acquired using SEM/EDS analysis, while the values of the carbon gained with the STEM are rather higher (carbonized sample). 

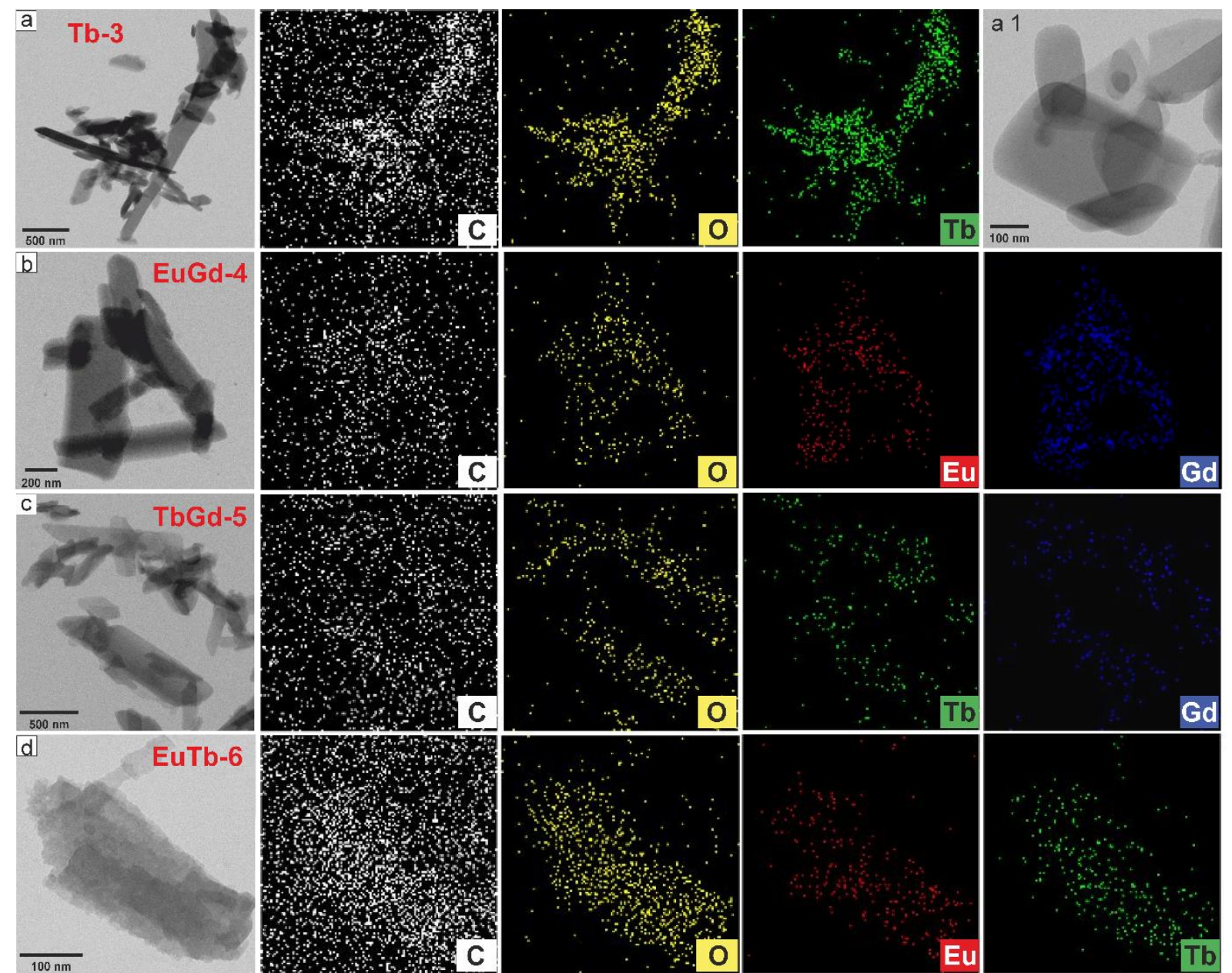

Figure 6. STEM images and EDS elemental mapping of the LnMOF powders: (a) Tb-3, (b) EuGd-4, (c) TbGd-5 and (d) EuTb-6 samples.

\subsection{Luminescence of the LnMOFs}

The luminescence tests were performed at room temperature. The excitation and emission spectra of the samples were recorded in a solid state. The excitation spectra of all of the LnMOFs provided a wide peak between 250 and $320 \mathrm{~nm}$, which contained two top bands at 260 and $300 \mathrm{~nm}$, cognated to the $\mathrm{Ln}^{3+}-\mathrm{O}^{2-}$ charge-transfer (CT) band and to the $\pi-\pi^{*}$ electron transformation of the organic ligand, respectively $[25,38,39]$.

When monitored at $543 \mathrm{~nm}$ (Figure 7a), the EuTb-6 and TbGd-5 MOF samples presented terbium transitions from the ${ }^{7} \mathrm{~F}_{6}$ ground to the ${ }^{5} \mathrm{D}_{1}(325 \mathrm{~nm}) ;{ }^{5} \mathrm{~L}_{7,8},{ }^{5} \mathrm{G}_{3}(340 \mathrm{~nm})$; ${ }^{5} \mathrm{~L}_{9},{ }^{5} \mathrm{D}_{2},{ }^{5} \mathrm{G}_{5}(351 \mathrm{~nm}) ;{ }^{5} \mathrm{~L}_{10}(368 \mathrm{~nm})$; and ${ }^{5} \mathrm{G}_{6},{ }^{5} \mathrm{D}_{3}(376 \mathrm{~nm})$ and ${ }^{5} \mathrm{D}_{4}(487 \mathrm{~nm})[25,40]$, whereas when monitoring at $617 \mathrm{~nm}$ (Figure $7 \mathrm{~b}$ ), EuTb-6 and EuGd-4 presented bands attributed to europium transitions from the ${ }^{7} \mathrm{~F}_{1}$ state to the ${ }^{5} \mathrm{D}_{1}$ excited state at $535 \mathrm{~nm}$, and from the ${ }^{7} \mathrm{~F}_{0}$ ground state to the ${ }^{5} \mathrm{D}_{1}(524 \mathrm{~nm}) ;{ }^{5} \mathrm{D}_{2}(464 \mathrm{~nm}) ;{ }^{5} \mathrm{D}_{3}(417 \mathrm{~nm}) ;{ }^{5} \mathrm{~L}_{6}(392 \mathrm{~nm})$; ${ }^{5} \mathrm{G}_{2}(383 \mathrm{~nm}) ;{ }^{5} \mathrm{D}_{4}(361 \mathrm{~nm})$ and ${ }^{5} \mathrm{H}_{6}(317 \mathrm{~nm})$ [41-44]. However, for the EuTb-6 MOF sample, even monitoring the Eu3+ ion at $617 \mathrm{~nm}, \mathrm{~Tb}^{3+}$ transitions were found from the ${ }^{7} \mathrm{~F}_{6}$ ground to the ${ }^{5} \mathrm{D}_{1}(325 \mathrm{~nm}) ;{ }^{5} \mathrm{~L}_{7,8},{ }^{5} \mathrm{G}_{3}(340 \mathrm{~nm}) ;{ }^{5} \mathrm{~L}_{9},{ }^{5} \mathrm{D}_{2},{ }^{5} \mathrm{G}_{5}(351 \mathrm{~nm}) ;{ }^{5} \mathrm{~L}_{10}(368 \mathrm{~nm})$; ${ }^{5} \mathrm{G}_{6},{ }^{5} \mathrm{D}_{3}(376 \mathrm{~nm})$ and ${ }^{5} \mathrm{D}_{4}(487 \mathrm{~nm})$, consequent from the energy between the $\mathrm{Tb}^{3+}$ and $\mathrm{Eu}^{3+}$ ions [25,38].

Figure 8a presents the emission spectra of the $\mathrm{Eu}^{3+}$ and $\mathrm{Tb}^{3+}$ ions of the mixed LnMOF samples. The spectra include the characteristic peaks of the $\mathrm{Eu}^{3+}$ ion for the EuTb-6 and EuGd-4 samples, which were assigned to transitions from the ${ }^{5} \mathrm{D}_{0}$ excited state to the ${ }^{7} \mathrm{~F}_{\mathrm{J}}$ $(\mathrm{J}=0,1,2,3$ and 4) ground states at 579, 591, 617, 653 and $702 \mathrm{~nm}$, respectively. Although the ${ }^{5} \mathrm{D}_{0} \rightarrow{ }^{7} \mathrm{~F}_{0}$ transformation is exactly forbidden according to the standard Judd-Ofelt theory, its occurrence can be explicated using J-mixing due to the crystal-field disorder, and 
its attendance shows that the $\mathrm{Eu}^{3+}$ ion takes place with $\mathrm{C}_{\mathrm{nv}}, \mathrm{C}_{\mathrm{n}}$ or $\mathrm{C}_{\mathrm{s}}$ symmetry [44-46]. The symmetrical profile of this band indicates only one component, confirming that the emission of the $\mathrm{Eu}^{3+}$ ion occurs from a single site in the matrix. Furthermore, as the band corresponding to the hypersensitive transition ${ }^{5} \mathrm{D}_{0} \rightarrow{ }^{7} \mathrm{~F}_{2}$ is more intense than the band due to the magnetic dipole transition ${ }^{5} \mathrm{D}_{0} \rightarrow{ }^{7} \mathrm{~F}_{1}$, the Eu ${ }^{3+}$ occupies a site without an inversion center $[44,46]$. For the EuTb-6 and TbGd-5 samples, bands related to the $\mathrm{Tb}^{3+}$ ion were observed at $492,543,585,620$ and $656 \mathrm{~nm}$, and they were ascribed to the ${ }^{5} \mathrm{D}_{4} \rightarrow{ }^{7} \mathrm{~F}_{\mathrm{J}}(\mathrm{J}=6,5$, 4,3 and 2) transitions, respectively [25,40].
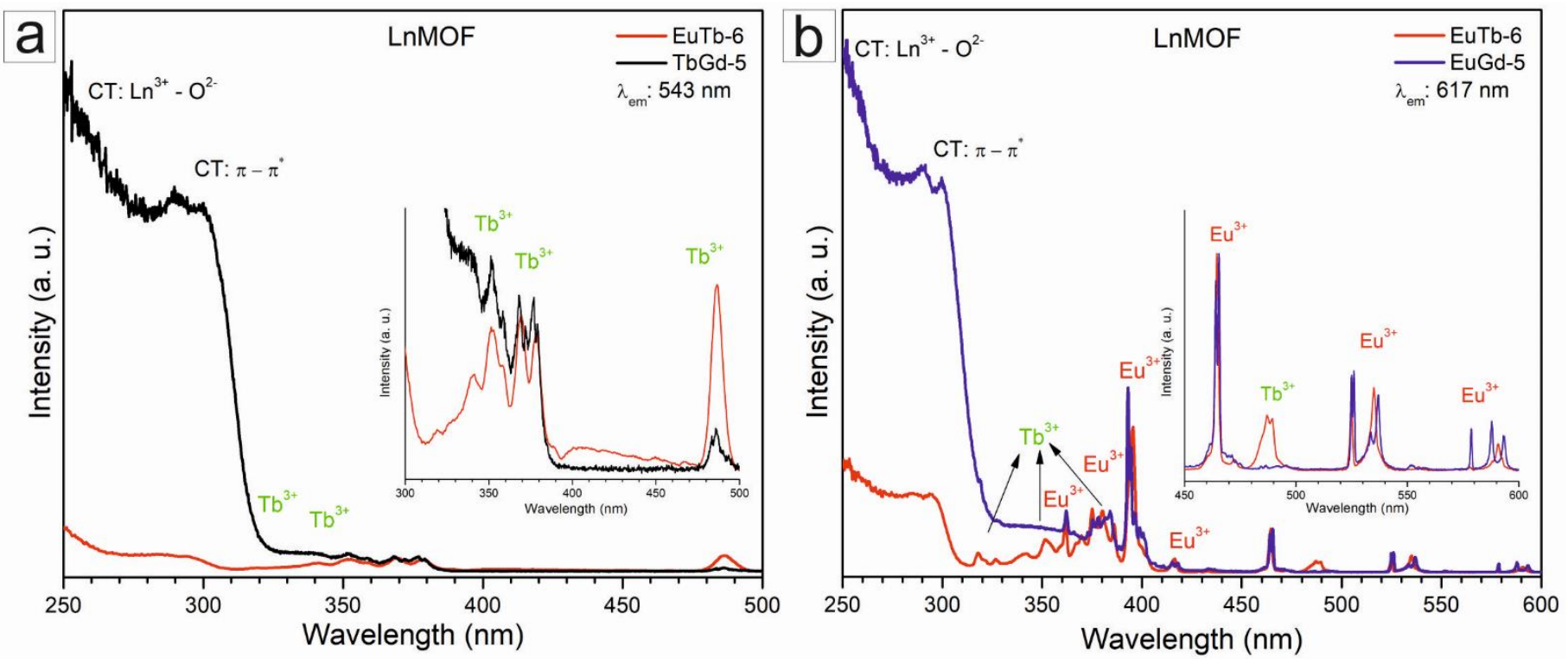

Figure 7. Excitation spectra of the LnMOF sample:s (a) EuTb-6 and TbGd-5 ( $\lambda_{\mathrm{em}}=543 \mathrm{~nm}$ ), and (b) EuTb-6 and EuGd-4 $\left(\lambda_{\mathrm{em}}=617 \mathrm{~nm}\right)$.

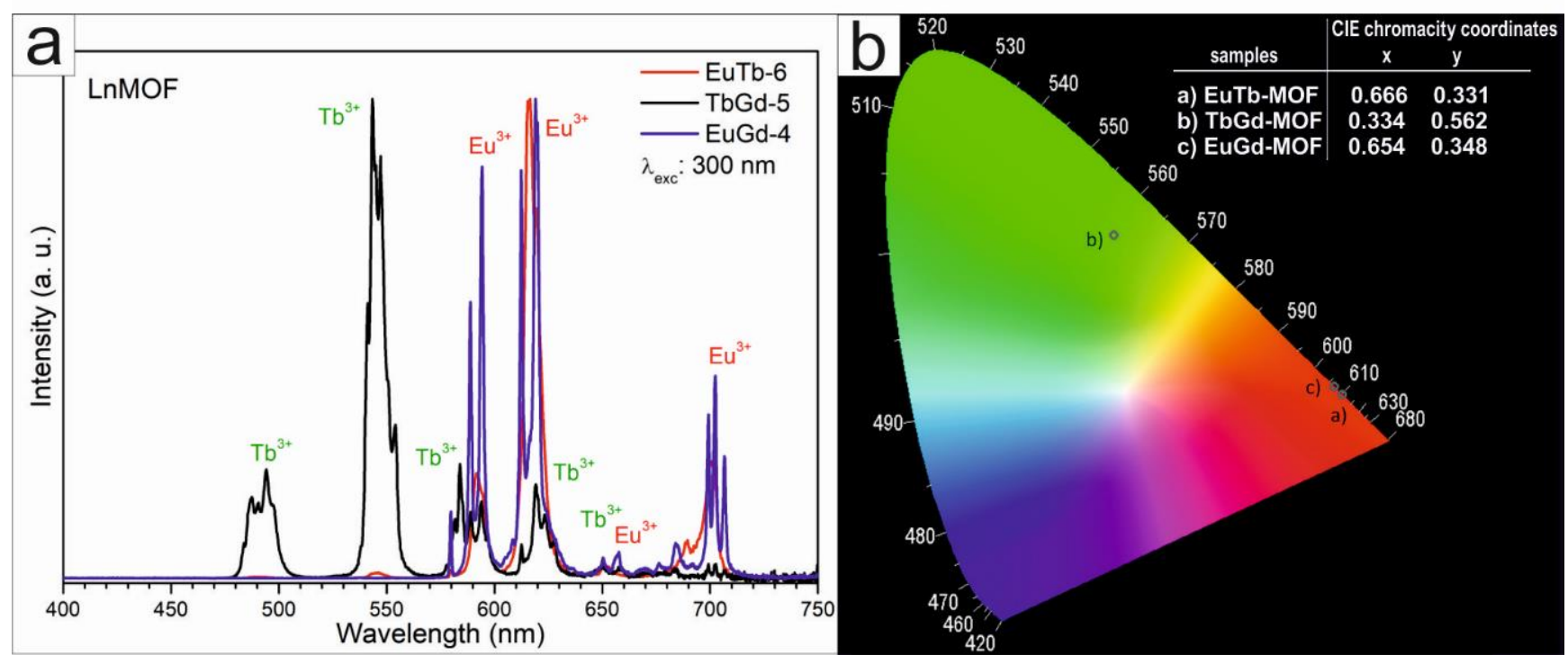

Figure 8. (a) Emission spectra and (b) CIE chromaticity diagrams of bimetallic lanthanide MOFs.

The CIE chromaticity coordinates were created by Spectra Lux 2.0 software [47] and the corresponding emission spectra acquired at room temperature (Figure 8b). As anticipated, the EuTb-6 and EuGd-4 samples showed CIE chromaticity coordinates closer to the default NTSC values $(x=0.670$ and $y=0.330)$ [48], but were better than the values desired for use in commercial phosphors than $\mathrm{Y}_{2} \mathrm{O}_{2} \mathrm{~S}: \mathrm{Eu}^{3+}$, which presents $\mathrm{x}=0.64$ and $\mathrm{y}=0.35$ [49]. The values of the CIE coordinates were $\mathrm{x}=0.666$ and $\mathrm{y}=0.331$, and $\mathrm{x}=0.654$ and $\mathrm{y}=0.348$ for 
the EuTb- 6 and EuGd- 4 samples, respectively. For the TbGd- 5 sample, the CIE chromaticity coordinates were $x=0.334$ and $y=0.562$, presenting emissions in the green region of the chromaticity diagram. The applications of the LnMOFs are listed in Table S3. The bimetallic LnMOFs can be used for applications as light-emitting materials [10,38], thermal sensors [20] or prototypical sensor to determine the concentrations of mixed organic compounds $[17,21,22,24]$ and $\mathrm{Fe}^{3+}$ ions [23].

\section{Conclusions}

In summary, the isostructural lanthanide metal-organic frameworks (LnMOFs $\left(\mathrm{Ln}=\mathrm{Eu}, \mathrm{Gd}, \mathrm{Tb}, \mathrm{Eu}_{0.5} \mathrm{Gd}_{0.5}, \mathrm{Gd}_{0.5} \mathrm{~Tb}_{0.5}\right.$ and $\left.\mathrm{Eu}_{0.5} \mathrm{~Tb}_{0.5}\right)$ ) were prepared by the solvothermal synthesis route. The series of nanostructured [ $\mathrm{Ln}(\mathrm{btc})]$ (BTC: 1,3,5-benzenetricarboxylate) were obtained using sodium acetate as a modulator. XPS corroborated the coordination impact among the europium, gadolinium and terbium ions and the BTC ligand. XPS established the presence of two valence-Eu and $\mathrm{Tb}-$ states $\left(\mathrm{Eu}^{3+} / \mathrm{Eu}^{2+}\right)$ and $\left(\mathrm{Tb}^{3+} / \mathrm{Tb}^{4+}\right)$ and a single valence, $\mathrm{Gd}$, state $\left(\mathrm{Gd}^{3+}\right)$. The various SEM and TEM morphologies of bimetallic [Ln(btc)] $\left(\mathrm{Eu}_{0.5} \mathrm{Gd}_{0.5}, \mathrm{Gd}_{0.5} \mathrm{~Tb}_{0.5}\right.$ and $\left.\mathrm{Eu}_{0.5} \mathrm{~Tb}_{0.5}\right)$ were changed depending on the synthesis chemistry composition of $\mathrm{Ln}^{3+}$ ions from nanorods $(100-300 \mathrm{~nm})$ for $\left[\mathrm{Eu}_{0.5} \mathrm{Gd}_{0.5}(\mathrm{btc})\right]$ and $\left[\mathrm{Gd}_{0.5} \mathrm{~Tb}_{0.5}\right.$ (btc)] to nanoparticles $(50-100 \mathrm{~nm})$ for $\left[\mathrm{Eu}_{0.5} \mathrm{~Tb}_{0.5}(\mathrm{btc})\right]$. The characteristic transitions within the $4 \mathrm{f}$ shells of the $\mathrm{Ln}^{3+}$ ions were shown in the luminescence spectra. The MOFs (EuTb and EuGd) presented CIE chromaticity coordinates in the red region. This CIE result $(x=0.666$ and $y=0.331)$ for the EuTb-MOF was expected due to its emissions from the europium ion, which were more intense than the terbium ion emissions. For TbGd-MOF, the CIE coordinates showed emissions in the green region of the chromaticity diagram. The mixed LnMOFs were prepared in order to extend their potential application in bifunctional luminescent sensors.

Supplementary Materials: The following are available online at https:/ /www.mdpi.com/article/10 .3390/inorganics9100077/s1. Figure S1: FTIR spectra of LnMOFs prepared by solvothermal synthesis. Figure S2: XRD patterns of LnMOFs prepared by solvothermal synthesis. Figure S3: XPS survey spectra of LnMOFs prepared by solvothermal synthesis. Table S1: XPS elemental atomic \% of the LnMOF samples. Figure S4: SEM morphology and TEM images (in insert) of TbMOF powders prepared by solvothermal synthesis (a) (DMF/H2O) and (c) (DMF/H2O/NaOAc), and (b,d) EDS spectra of TbBTC. Table S2: EDS analysis of Tb-3, EuGd-4, TbGd-5 and EuTb-6 samples from the TEM/EDS spectra.

Author Contributions: Investigation, conceptualization, resources, writing—original draft preparation, H.B.; writing-review and editing, methodology, H.B., E.M. and L.R.; investigation and formal analysis, E.N., W.N., H.K., M.L., A.K., Z.M., M.S. and L.M. All authors have read and agreed to the published version of the manuscript.

Funding: The research was supported by the Grant Agency of the Slovak Academy of Sciences through project VEGA No. 2/0037/20 and APVV-20-0299. The authors thank Coordenação de Aperfeiçoamento de Pessoal de Nível Superior-Brasil (CAPES)-Finance Code 001, Conselho Nacional de Desenvolvimento Científico e Tecnológico (CNPq, grants: 302702/2018-0 L.A.R. and 302668/2017-9 E.J.N.).

Data Availability Statement: The data presented in this study are available on request from the corresponding author. This data is not publicly available due to its excessive size and complex format.

Conflicts of Interest: The authors declare no conflict of interest.

\section{References}

1. Batten, S.R.; Champness, N.R.; Chen, X.M.; Garcia-Martinez, J.; Kitagawa, S.; Öhrström, L.; O'Keeffe, M.; Suh, M.P.; Reedijk, J. Terminology of metal-organic frameworks and coordination polymers (IUPAC Recommendations 2013). Pure Appl. Chem. 2013, 85, 1715-1724. [CrossRef]

2. Peedikakkal, A.M.P.; Adarsh, N.N. Coordination Polymers. In Porous Coordination Polymers; Mazumder, M.J., Sheardown, H., Al-Ahmed, A., Eds.; Springer: Berlin/Heidelberg, Germany, 2018; pp. 2-6. [CrossRef]

3. Lee, J.S.M.; Otake, K.; Kitagawa, S. Transport properties in porous coordination polymers. Coord. Chem. Rev. 2020, $421,213447$. [CrossRef] 
4. Kuznetsova, A.; Matveevskaya, V.; Pavlov, D.; Yakunenkov, A.; Potapov, A. Coordination Polymers Based on Highly Emissive Ligands: Synthesis and Functional Properties. Materials 2020, 13, 2699. [CrossRef] [PubMed]

5. Kovalenko, K.A.; Potapov, A.S.; Fedin, V.P. Micro- and mesoporous metal-organic coordination polymers for separation of hydrocarbons. Rus. Chem. Rev. 2021, 90. [CrossRef]

6. Xu, B.; Guo, H.; Wang, S.; Li, Y.; Zhang, H.; Liu, C. Solvothermal synthesis of luminescent Eu(BTC)( $\left.\mathrm{H}_{2} \mathrm{O}\right) \mathrm{DMF}$ hierarchical architectures. CrystEngComm 2012, 14, 2914-2919. [CrossRef]

7. Neufeld, M.J.; Winter, H.; Landry, M.R.; Goforth, A.M.; Khan, S.; Pratx, G.; Sun, C. Lanthanide Metal-Organic Frameworks for Multispectral Radioluminescent Imaging. ACS Appl. Mater. Interfaces 2020, 12, 26943-26954. [CrossRef]

8. Huang, Z.; Zhao, F.; Fan, L.; Zhao, W.; Chen, B.; Chen, X.; Zhou, S.F.; Xiao, J.; Zhan, G. Improved hydrolytic robustness and catalytic performance of flexible lanthanide-based metal-organic frameworks: A mater of coordination environments. Mater. Des. 2020, 194, 108881. [CrossRef]

9. Dang, S.; Song, S.; Feng, J.; Zhang, H. Microwave-assisted synthesis of nanoscale Eu(BTC)( $\left.\mathrm{H}_{2} \mathrm{O}\right)$. DMF with tunable luminescence. Sci. China Chem. 2015, 58, 973-978. [CrossRef]

10. Alammar, T.; Hlova, I.Z.; Gupta, S.; Balema, V.; Pecharskya, V.K.; Mudring, A.V. Luminescent Properties of Mechanochemically Synthesized Lanthanide Containing MIL-78 MOF. Dalton Trans. 2018, 47, 7594-7601. [CrossRef] [PubMed]

11. Ramya, A.R.; Varughese, S.; Reddy, M.L.P. Tunable white-light emission from mixed lanthanide $\left(\mathrm{Eu}^{3+}, \mathrm{Gd}^{3+}, \mathrm{Tb}^{3+}\right)$ coordination polymers derived from 4-(dipyridin-2-yl)-aminobenzoate. Dalton Trans. 2014, 43, 10940-10946. [CrossRef]

12. Gonzalez, A.; Chu, X.M.; Pitton, K.A.; Crichton, R.; Einkauf, J.D. Developing Luminescent Lanthanide Coordination Polymers and Metal-Organic Frameworks for Bioimaging Applications. Springs 2017, 6, 37-43.

13. Zhao, Y.; Li, D. Lanthanide-functionalized metal-organic frameworks as ratiometric luminescent sensors. J. Mater. Chem. C 2020, 8, 12739-12754. [CrossRef]

14. Wang, M.; Hu, M.; Li, Z.; He, L.; Song, Y.; Jia, Q.; Zhang, Z.; Du, M. Construction of Tb-MOF-on-Fe-MOF conjugate as a novel platform for ultrasensitive detection of carbohydrate antigen 125 and living cancer cells. Biosens. Bioelectron. 2019, 142, 111536. [CrossRef]

15. Nasruddin; Zulys, A.; Yulia, F.; Buhori, A.; Muhadzib, N.; Ghiyats, M.; Saha, B.B. Synthesis and characterization of a novel microporous lanthanide based metal-organic framework (MOF) using napthalenedicarboxylate acid. J. Mater. Res. Technol. 2020, 9, 7409-7417. [CrossRef]

16. Lian, X.; Yan, B. A lanthanide metal-organic framework (MOF-76) for adsorbing dyes and fluorescence detecting aromatic pollutants. RSC Adv. 2016, 6, 11570-11576. [CrossRef]

17. Zhang, Y.; Li, B.; Ma, H.; Zhang, L.; Jiang, H.; Song, H.; Zhang, L.; Luo, Y. A nanoscaled lanthanide metal-organic framework as a colorimetric fluorescent sensor for dipicolinic acid based on modulating energy transfer. J. Mater. Chem. C 2016, 4, 7294-7301. [CrossRef]

18. Ren, K.; Guo, X.F.; Tang, Y.J.; Huang, B.H.; Wang, H. Size-controlled synthesis of metal-organic frameworks and their performance as fluorescence sensors. Analyst 2020, 145, 7349-7356. [CrossRef] [PubMed]

19. Nascimento, J.F.S.D.; Barros, B.S.; Kulesza, J.; de Oliveira, J.B.L.; Leite, A.K.P.; de Oliveira, R.S. Influence of synthesis time on the microstructure and photophysical properties of Gd-MOFs doped with Eu ${ }^{3+}$. Mater. Chem. Phys. 2017, 190, 166-174. [CrossRef]

20. Gomez, G.E.; Kaczmarek, A.M.; Van Deun, R.; Brusau, E.V.; Narda, G.E.; Vega, D.; Iglesias, M.; Gutierrez-Puebla, E.; Monge, M.A Photoluminescence, Unconventional-Range Temperature Sensing, and Efficient Catalytic Activities of Lanthanide Metal-Organic Frameworks. Eur. J. Inorg. Chem. 2016, 10, 1577-1588. [CrossRef]

21. Chen, D.M.; Sun, C.X.; Peng, Y.; Zhang, N.N.; Si, H.H.; Liu, C.S.; Du, M. Ratiometric fluorescence sensing and colorimetric decoding methanol by a bimetallic lanthanide-organic framework. Sens. Actuators B 2018, 265, 104-109. [CrossRef]

22. Zhou, J.; Li, H.; Zhang, H.; Li, H.; Shi, W.; Cheng, P. A Bimetallic Lanthanide Metal-Organic Material as a Self-Calibrating Color-Gradient Luminescent Sensor. Adv. Mater. 2015, 27, 7072-7077. [CrossRef] [PubMed]

23. Cheng, X.; Hu, J.; Li, J.; Zhang, M. Tunable emission and selective luminescence sensing for nitro-pollutants and metal ions based on bifunctional lanthanide metal-organic frameworks. J. Lumin. 2020, 221, 117100. [CrossRef]

24. Xia, T.; Wang, J.; Jiang, K.; Cui, Y.; Yang, Y.; Qian, G. A Eu/Gd-mixed metal-organic framework for ultrasensitive physiological temperature sensing. Chin. Chem. Lett. 2018, 29, 861-864. [CrossRef]

25. Brunckova, H.; Mudra, E.; Rocha, L.; Nassar, E.; Nascimento, W.; Kolev, H.; Kovalcikova, A.; Molcanova, Z.; Podobova, M.; Medvecky, L. Preparation and characterization of isostructural lanthanide Eu/Gd/Tb metal-organic framework thin films for luminescent applications. Appl. Surf. Sci. 2021, 542, 148731. [CrossRef]

26. Che, H.; Li, Y.; Zhang, S.; Chen, W.; Tian, X.; Yang, C.; Lu, L.; Zhou, Z.; Nie, Y. A portable logic detector based on Eu-MOF for multi-target, on-site, visual detection of $\mathrm{Eu}^{3+}$ and fluoride in groundwater. Sens. Actuators B Chem. 2020, 324, 128641. [CrossRef]

27. Binh, N.T.; Tien, D.M.; Giang, L.T.K.; Khuyen, H.T.; Huong, N.T.; Huong, T.T.; Lam, T.D. Study on preparation and characterization of MOF based lanthanide doped luminescent coordination polymers. Mater. Chem. Phys. 2014, 143, 946-951. [CrossRef]

28. Song, K.; Yu, H.; Zhang, J.; Bai, Y.; Guan, Y.; Yu, J.; Guo, L. Rosebengal-Loaded Nanoporous Structure Based on Rare Earth Metal-Organic-Framework: Synthesis, Characterization and Photophysical Performance. Crystals 2020, 10, 185. [CrossRef]

29. Li, G.; Tong, C. Dual-functional lanthanide metal organic frameworks for visual and ultrasensitive ratiometric fluorescent detection of phosphate based on aggregation-induced energy transfer. Anal. Chimica Acta 2020, 1133, 11-19. [CrossRef] [PubMed] 
30. Colomer, M.T.; Rodríguez, E.; Moran-Pedroso, M.; Vattier, F.; de Andres, A. Impact of Tb ${ }^{4+}$ and morphology on the thermal evolution of Tb-doped $\mathrm{TiO}_{2}$ nanostructured hollow spheres and nanoparticles. J. Alloys Compd. 2020, 853, 156973. [CrossRef]

31. Balaguer, M.; Yoo, C.Y.; Bouwmeester, H.J.M.; Serra, J.M. Bulk transport and oxygen surface exchange of the mixed ionic-electronic conductor $\mathrm{Ce}_{1-x} \mathrm{~Tb}_{x} \mathrm{O}_{2-\delta}(x=0.1,0.2,0.5)$. J. Mater. Chem. A 2013, 1, 10234-10242. [CrossRef]

32. Cheng, J.; Liang, J.; Dong, L.; Chai, J.; Zhao, N.; Ullah, S.; Wang, H.; Zhang, D.; Imtiaz, S.; Shan, G.; et al. Self-assembly of 2D-metal-organic framework/graphene oxide membranes as highly efficient adsorbents for the removal of $\mathrm{Cs}^{+}$from aqueous solutions. RSC Adv. 2018, 8, 40813-40822. [CrossRef]

33. Li, X.; Zhang, J.; Han, Y.; Zhu, M.; Shang, S.; Li, W. MOF-derived various morphologies of N-doped carbon composites for acetylene hydrochlorination. J. Mater. Sci. 2018, 53, 4913-4926. [CrossRef]

34. Jiang, T.; Sun, X.; Wei, L.; Li, M. Electrochemical determination of artemisinin based on signal inhibition for the reduction of hemin. Anal. Bioanal. Chem. 2021, 413, 565-576. [CrossRef] [PubMed]

35. Fechler, N.; Fellinger, T.P.; Antonietti, M. One-pot synthesis of nitrogen-sulfur-co-doped carbons with tunable composition using a simple isothiocyanate ionic liquid. J. Mater. Chem. A 2013, 1, 14097-14102. [CrossRef]

36. Sheta, S.M.; El-Sheikh, S.M.; Abd-Elzaher, M.M.; Wassel, A.R. A novel nano-size lanthanum metal-organic framework based on 5-amino-isophthalic acid and phenylenediamine: Photoluminescence study and sensing applications. Appl. Organometal Chem. 2019, 33, 4777. [CrossRef]

37. Du, S.Z.; Sun, Z.; Han, L.; Qing, M.; Luo, H.Q.; Li, N.B. Two 3d-4f metal-organic frameworks as fluorescent sensor array for the discrimination of phosphates based on different response patterns. Sens. Actuators B. Chem. 2020, 324, 128757. [CrossRef]

38. Zheng, Y.; Liu, K.; Sun, X.; Guan, R.; Su, H.; You, H.; Qi, C. A series of nano/micro-sized metal-organic frameworks with tunable photoluminescence properties. CrystEngComm 2015, 17, 2321-2326. [CrossRef]

39. Medina-Velazquez, D.Y.; Alejandre-Zuniga, B.Y.; Loera-Serna, S.; Ortiz, E.M.; Morales-Ramirez, J.; Garfias-Garcia, E.; GarciaMurillo, A.; Falcony, C. An alkaline one-pot reaction to synthesize luminescent Eu-BTC MOF nanorods, highly pure and water-insoluble, under room conditions. J. Nanoparticle Res. 2016, 18, 352-362. [CrossRef]

40. Moscardini, S.B.; Sverzut, L.; Massarotto, W.L.; Nassar, E.J.; Rocha, L.A. Multi-color emission from lanthanide ions doped into niobium oxide. J. Mater. Sci. Mater Electron. 2020, 31, 5241-5252. [CrossRef]

41. Miura, B.A.; Ferreira, N.H.; Oliveira, P.F.; Faria, E.H.; Tavares, D.C.; Rocha, L.A.; Ciuffi, K.J.; Nassar, E.J. Functionalization of luminescent $\mathrm{YVO}_{4}: \mathrm{Eu}^{3+}$ nanoparticles by sol-gel. J. Lumin. 2015, 159, 93-99. [CrossRef]

42. Rocha, L.A.; Ciuffi, K.J.; Sacco, H.C.; Nassar, E.J. Influence on deposition speed and stirring type in the obtantion of titania films. Mater. Chem. Phys. 2004, 85, 245-250. [CrossRef]

43. Haugland, R.P. Handbook of Fluorescent Probes and Research Products, 9th ed.; Molecular Probes: Eugene, OR, USA, 2002.

44. Binnemans, K. Interpretation of europium(III) spectra. Coord. Chem. Rev. 2015, 295, 1-45. [CrossRef]

45. Matias, C.R.; Nassar, E.J.; Verelst, M.; Rocha, L.A. Synthesis and Characterization of $\mathrm{Nb}_{2} \mathrm{O}_{5}: \mathrm{La}^{3+}$,Eu ${ }^{3+}$ Phosphors Obtained by the Non-Hydrolytic Sol-Gel Process. J. Braz. Chem. Soc. 2015, 26, 2558-2570. [CrossRef]

46. Pereira, P.F.S.; Matos, M.G.; Ferreira, C.M.A.; De Faria, E.H.; Calefi, P.S.; Rocha, L.A.; Ciuffi, K.J.; Nassar, E.J. Aluminate matrix doped with $\mathrm{Tm}^{3+} / \mathrm{Tb}^{3+} / \mathrm{Eu}^{3+}$ obtained by non-hydrolytic sol-gel route: White light emission. J. Lumin. 2014, 146, 394-397. [CrossRef]

47. Santa-Cruz, P.A.; Teles, F.S. Spectra Lux Software v.1.0, Ponto Quântico Nanodispositivos/Renami; SciELO: São Paulo, Brazil, 2003.

48. Zhou, L.; Huang, J.; Gong, F.; Lan, Y.; Tong, Z.; Sun, J. A new red phosphor LaNb ${ }_{0.70} \mathrm{~V}_{0.30} \mathrm{O}_{4}$ :Eu ${ }^{3+}$ for white light-emitting diodes. J. Alloys Compd. 2010, 495, 268-271. [CrossRef]

49. Huang, J.; Zhou, L.; Liang, Z.; Gong, F.; Han, J.; Wang, R. Promising red phosphors $\mathrm{LaNbO}_{4}: \mathrm{Eu}^{3+}$, $\mathrm{Bi}^{3+}$ for LED solid-state lighting application. J. Rare Earths 2010, 28, 356-360. [CrossRef] 